Wellesley College

Wellesley College Digital Scholarship and Archive

Biological Sciences Faculty Scholarship

Biological Sciences

1991

\title{
Surviving the Big Chill: Overwintering Strategies of Aquatic and Terrestrial Insects
}

Marianne V. Moore

Wellesley College

Richard E. Lee Jr.

Miami University - Hamilton

Follow this and additional works at: http://repository.wellesley.edu/biologicalsciencesfaculty

\section{Recommended Citation}

Moore, Marianne V. and Lee, Richard E. Jr., "Surviving the Big Chill: Overwintering Strategies of Aquatic and Terrestrial Insects" (1991). Biological Sciences Faculty Scholarship. Paper 4.

http://repository.wellesley.edu/biologicalsciencesfaculty/4 accepted for inclusion in Biological Sciences Faculty Scholarship by an authorized administrator of Wellesley College Digital Scholarship and Archive. For more information, please contact ir@wellesley.edu. 


\title{
Surviving the Big Chill: Overwintering Strategies of Aquatic and Terrestrial Insects
}

\author{
Marianne V. Moore and Richard E. Lee, Jr.
}

\begin{abstract}
The purpose of this paper is to describe the coldhardiness of aquatic insects and to use the literature to compare physiological and behavioral strategies that aquatic and terrestrial insects use to cope with minimum winter temperatures. In sharp contrast to terrestrial insects, aquatic insects from seven different orders had limited ability to supercool and did so to temperatures of only -3 to $-7^{\circ} \mathrm{C}$. Inability to supercool may be due to inoculative freezing - the penetration of external ice crystals through pores or orifices of the insect's cuticle. Furthermore, our results suggest that terrestrial adult stages of aquatic insects may have greater capacity to supercool than aquatic stages of the same taxon. Our results and others' suggested that few aquatic species are freeze tolerant, and those that are appear to be restricted to the order Diptera. Consequently, behavioral avoidance of ice or the capacity to remain unfrozen while encased in ice may be particularly important for overwintering aquatic insects. Ecological implications of insect coldhardiness at the individual, population, and community level are discussed for both terrestrial and aquatic insects.
\end{abstract}

$\mathrm{M}$ ANY AQUATIC AND TERRESTRIAL insects risk or experience exposure to subzero temperatures during winter months in temperate climates. Because such temperatures are potentially lethal, insects exhibit diverse strategies for coping with extreme cold. For example, monarch butterflies may migrate $\approx 1,600 \mathrm{~km}$ to warmer climates. In rivers, some mayfly nymphs migrate from shallow, near-shore waters into deeper channels where ice does not form (Olsson 1983). Still other insects seek protected microhabitats by burrowing into leaf litter or pond sediments where temperatures are more benign (Danks 1978). Some insects, however, remain in exposed frigid habitats and survive. For example, freezetolerant larvae of Eurosta solidaginis (Diptera: Tephritidae) survive temperatures of $-55^{\circ} \mathrm{C}$ in galls of exposed goldenrod stems (Salt 1961). Likewise, aquatic insects such as chironomid larvae become encased in ice of frozen ponds yet resume normal activity with springtime thawing. These insects are not frozen in a state of suspended animation, but instead they adapt and respond to subfreezing temperatures through a process called cold-hardening that involves complex physiological and biochemical changes.

During the last several decades, much has been learned about insect cold-hardiness-the capacity of terrestrial insects to survive longterm or short-term exposure to low temperatures. Yet little is known about this phenomenon in aquatic insects. We began an investigation of cold-hardiness in aquatic insects that revealed striking differences between terrestrial and aquatic species. To put our work in context, we first compare the overwintering habitats and temperatures that aquatic and terrestrial insects encounter. Then we discuss cold-hardiness, as well as behaviors that these two insect groups use to cope with subzero temperatures. Lastly, we briefly explore the ecological consequences of overwintering and highlight potential applications of insect cold-hardiness to pest management.

\section{Overwintering Habitats and Temperatures}

Terrestrial Insects. Short photoperiods and low or subzero temperatures stimulate insects to seek overwintering sites (Danks 1978). After the first frost, many terrestrial arthropods quickly change habitats. One of the more dramatic examples is the movement of the ground-dwelling carabid beetles Pterostichus brevicornis Kirby after a frost into hollows and passageways of tree stumps, where aggregations of $>1,000$ individuals are common (Baust 1976). Observations strongly suggest that some insects precisely choose their overwintering sites on the basis of size, shelter, position, and moisture content. A seasonal negative phototaxis causes some insects, such as mosquitoes, to move into dark hollows, caves, or litter, which then become their overwintering sites (Danks 1978). Some insects that cannot tolerate freezing avoid moist sites because contact with water, even dew or frost that develops on the insect's cuticle, triggers freezing that is fatal (Salt 1963, Layne et al. 1990).

Most terrestrial insects overwinter within sheltered sites, such as leaf litter, snow, soil, or decayed tree stumps (Danks 1978). Here, low temperatures are ameliorated by the insulating properties of snow, porous wood, or soil. For example, a snow depth of $\approx 25 \mathrm{~cm}$ will attenuate air temperatures of -20 to $\approx 0^{\circ} \mathrm{C}$ immediately below the snow layer (Duffy \& Liston 1985). The insulative capacity of snow is a function of its depth and density (Marchand 1982). Porous wood of decayed tree stumps is also a good insulator because it retains water, which buffers this environment from extreme temperature changes. Below the soil surface, temperature increases linearly with depth in winter. Yet terrestrial insects usually overwinter in the top $15 \mathrm{~cm}$ of soil, even though temperatures are warmer at greater depths (Danks 1978). Insects seldom burrow deeply because burrowing is energetically costly, and deeper sites warm more slowly in spring. Delay in the onset of growth the following spring may put burrowers at a disadvantage, because suitable temperatures will resume at a later date than in shallower sites. A deep overwintering site may mean high survivorship of harsh winter temperatures but a spring-summer season that is too short for successful growth and maturation. This is particularly critical in boreal and polar regions where the growing season is extremely short. Interestingly, it is common for insects in the high arctic to overwinter on exposed rocks and experience severe winter temperatures, but these insects initiate growth as soon as air temperatures begin to warm-a process which ensures completion of the life cycle (Danks 1978). Thus, overwin- 
tering insects must balance the trade-off between protection from environmental extremes and an appropriate time for the onset of growth in spring.

Insects overwintering above the snow (e.g., under bark, on twigs) experience colder temperatures than those living in the soil (Table 1). Aspect greatly influences the temperatures of microhabitats above the snow. For example, in the Northern Hemisphere, south-facing microhabitats receive more solar radiation, resulting in greater daily maxima and higher mean temperatures than north-facing sites. Daily temperature variation in such microhabitats is greater in winter, when there is no shading by leaves, than in summer (Danks 1978).

Aquatic Insects. Temperatures in ice-free or frozen lakes and streams are generally warmer and less variable than those in terrestrial microhabitats (Table 1). This is because water has a higher specific heat than air, thus preventing extreme ranges in water temperature. Also, aquatic habitats commonly develop a layer of surface ice or sometimes freeze solid, thus insulating the underlying water or substrate from frigid air temperatures and windchill. Once water freezes, ice will cool to subzero temperatures. Ice, however, is an effective insulator. Hence, its lowest recorded field temperatures are $\approx 25^{\circ} \mathrm{C}$ warmer than lowest recorded air temperatures (Table 1). Therefore, submerged aquatic insects, as well as those encased in ice, are likely to experience warmer winter temperatures than many terrestrial insects, particularly those in exposed microhabitats.

Most aquatic insects overwinter in an egg or larval stage, and some species such as mayflies and blackflies feed and grow in the water under ice (Bengtsson 1981, Merritt et al. 1982). These winter-active insects are probably the most likely to move from microhabitats that become threatened by a freezing event. Other insects, however, become embedded in ice and experience subzero temperatures. Freezing of the water and underlying sediments occurs in aestival lakes, shallow temporary ponds, tree holes, the littoral zone of streams and lakes, and sometimes the substrate of shallow turbulent streams. Aestival lakes, largely confined to alpine and arctic regions, are permanent water bodies that freeze to the bottom during winter months. Chironomid (tendipedid) larvae and occasionally Odonata (coenagrionid) nymphs overwinter in these frozen habitats, and they have been collected alive from the ice (Neldner \& Pennak 1955, Daborn 1974). Temporary ponds, particularly during drought years, also may freeze solid. Larvae of some tree-hole mosquitoes survive freezing of water within their hibernacula (Copeland \& Craig 1990). In lowgradient streams and rivers, littoral-dwelling caddisflies and chironomids may become trapped when both water and sediments freeze (Olsson 1981). Stream-dwelling insects also may encounter anchor ice, a soft, slushy ice that forms on the bottom of shallow, turbulent streams that lack an ice cover. Under such conditions, the streambed loses heat, supercools, and ice crystals attach to the substrate and grow. Live Plecoptera, Ephemeroptera, Trichoptera, Diptera, and Coleoptera have been recovered from anchor ice after thawing (Benson 1955).

Not all aquatic insects, however, overwinter in aquatic habitats. For example, adult caddisflies (Psychoglypha subborealis (Banks) and Glyphopsyche irrorata (F.)) (Trichoptera: Limnephilidae) were collected monthly during winter in the terrestrial environment near Juneau, Alaska, when minimum air temperatures ranged from -2 to $-30^{\circ} \mathrm{C}$ (Ellis 1978). A life history study of G. irrorata near Calgary, Alberta, confirmed that this caddisfly emerges in September and overwinters as a terrestrial adult, a life history strategy which appears to be an adaptation for life in temporary ponds that experience winter drought (Berte \& Pritchard 1983). Other aquatic insects such as winter stoneflies (Order Plecoptera, certain members of Capniidae and Taeniopterygidae families) crawl through tunnels or cracks in stream ice to emerge as adults. In southern Ontario, one species, Allocapnia pygmaea (Burmeister), emerges during late February through March, when air temperatures usually range from -17 to $0^{\circ} \mathrm{C}$ (Harper \& Hynes 1972). According to anecdotal reports, adults crawl under snow, where winter air temperatures are moderated. Perhaps more.unusual is the adult stonefly Zapada cinctipes (Banks) (Plecoptera: Nemouridae), which reenters water when air temperatures drop below $0^{\circ} \mathrm{C}$ (Tozer 1979). Very infrequently, larval stages of aquatic insects overwinter in terrestrial environments. For example, the limnephilid caddisflies Limnepbilus externus Hagen and Anabolia bimaculata (Walker) are reported to overwinter as first instars on the ground above water level in southern Alberta, Canada (Berte \& Pritchard 1986). In general, very little is known about the environmental conditions experienced by terrestrial stages of aquatic insects during winter or about the location of their winter microhabitats.

\section{Insect Cold-Hardiness}

Terrestrial Insects. Although a cozy overwintering site certainly helps insects survive winter, they also must possess some degree of cold-hardiness. Winter cold-hardiness is achieved through physiological and biochemical processes that take several or more weeks to complete. These processes are the focus of research about insect cold-hardiness, a relatively young field that began with the pioneering work of R. W. Salt in the 1950s and 1960s. Research by Salt (1961) and others shows that terrestrial insects survive subzero temperatures by employing one of two strategies: (1) avoiding freezing, or (2) tolerating freezing of their body fluids. Insects employing the former strategy are called freeze susceptible, and those exhibiting the latter are called freeze tolerant.

Freeze-Susceptible Insects. These insects will not survive if their body fluids freeze. To avoid this, the insects maintain body fluids in a liquid state (e.g., supercool) at tempetatures below the melting point of the hemolymph. Supercooling is not, however, an extraordinary phenomenon unique to insects and other terrestrial arthropods. Small volumes of tap water $(5 \mu \mathrm{l})$ can be supercooled to temperatures $\leq-18^{\circ} \mathrm{C}$ without ice nucleation occurring spontaneously. The capacity to supercool decreases with increasing volume and progressively longer periods of exposure. In a physical sense, insects are comparable to small volumes of water and thereby possess an intrinsic capacity to supercool. Many freeze-susceptible insects, however, supercool to even lower temperatures, ranging between -15 and $-35^{\circ} \mathrm{C}$ or lower. This is adaptive because they must supercool below the temperature of their hibernacula to survive. Often the lowest supercooling values of freeze-susceptible insects approximate the minimum climatic temperature occurring in an insect's geographical range (Danks 1978). In northern Canada and Alaska, larvae of several gall-forming hymenopterans and dipterans supercool to temperatures $<-60^{\circ} \mathrm{C}$ (Ring \& Tesar 1981).

Freeze-susceptible insects enhance their ability to supercool by synthesizing a variety of compounds that function as antifreeze agents to decrease the temperature at which ice nucleation occurs within body fluids, termed the supercooling point (Lee 1989). These chemicals are synthesized in preparation for winter as part of the coldhardening process. The most common low-molecular-weight antifreeze in insects is glycerol, although other polyhydric alcohols (e.g-, sorbitol and mannitol), sugars (trehalose and fructose), and antifreeze proteins also are produced (Storey \& Storey 1991, Duman et al. 1991).

Ice-nucleating agents provide an initial seed or "nucleus" that catalyzes ice formation. Within the insect, these substances are believed to be the primary factor regulating supercooling capacity (Lee 1991). Even if the insect has accumulated high concentrations of cryoprotectants, supercooling can be considerably limited when ice nucleators are present. Frequently, freeze-susceptible insects can improve their capacity to supercool by fasting or evacuating their guts of food residue, dust, or bacteria that may act as ice nucleators (see 
Table 1. Minimum winter temperatures recorded in aquatic and terrestrial habitats where insects were collected

\begin{tabular}{|c|c|}
\hline Habitat description & $\begin{array}{l}\text { Geographic location } \\
\text { and latitude }\end{array}$ \\
\hline
\end{tabular}

Aquatic habitats

Lake (surface sediments under ice in littoral zone)

Northwest Territories, Canada, $71^{\circ} 42^{\prime} \mathrm{N}$

Tree hole (ice $2 \mathrm{~cm}$ below surface)

Pond (ice several $\mathrm{cm}$ below surface)

Pond (mud sediments below $15-25 \mathrm{~cm}$ of ice)

Boreal river (sediment surface below $35 \mathrm{~cm}$ ice in littoral zone)

Boreal river (sediment surface under ice)

Temperate river (ice)

Terrestrial habitats

Screen air

Sod (10 cm deep)

Sod $(20 \mathrm{~cm}$ deep)

Sod (50 cm deep)

Sod (100 cm deep)

Screen air

Tree bark

Sod (10 cm deep)

Sod $(20 \mathrm{~cm}$ deep)

Sod $(50 \mathrm{~cm}$ deep $)$

Sod (100 cm deep)
Indiana, $41^{\circ} 42^{\prime} \mathrm{N}$

Alberta, Canada, $53^{\circ} 31^{\prime} \mathrm{N}$

Ontario, Canada, $45^{\circ} 24^{\prime} \mathrm{N}$

Sweden, $71^{\circ} 42^{\prime} \mathrm{N}$

Sweden, $71^{\circ} 42^{\prime} \mathrm{N}$

Michigan, $46^{\circ} 28^{\prime} \mathrm{N}$

Saskatchewan, Canada, $52^{\circ} 08^{\prime} \mathrm{N}$

Saskatchewan, Canada, $52^{\circ} 08^{\prime} \mathrm{N}$

Saskatchewan, Canada, $52^{\circ} 08^{\prime} \mathrm{N}$

Saskatchewan, Canada, $52^{\circ} 08^{\prime} \mathrm{N}$

Saskatchewan, Canada, $52^{\circ} 08^{\prime} \mathrm{N}$

Ontario, Canada, $45^{\circ} 24^{\prime} \mathrm{N}$

Ontario, Canada, $45^{\circ} 24^{\prime} \mathrm{N}$

Ontario, Canada, $45^{\circ} 24^{\prime} \mathrm{N}$

Ontario, Canada, $45^{\circ} 24^{\prime} \mathrm{N}$

Ontario, Canada, $45^{\circ} 24^{\prime} \mathrm{N}$

Ontario, Canada, $45^{\circ} 24^{\prime} \mathrm{N}$

$\begin{array}{cl}-18 & \text { Andrews \& Rigler } 1985 \\ -15.5 & \text { Copeland \& Craig 1990 } \\ -8 & \text { Daborn 1971 } \\ -0.9 \text { to }-2.6 & \text { Danks 1978 } \\ -2.7 & \text { Olsson 1988 } \\ -4.0 & \text { Olsson 1984 } \\ -2.0^{\star} & \text { Duffy \& Liston 1985 }\end{array}$

-43.9 Danks 1978

-8.9 Danks 1978

-8.3 Danks 1978

-5.0 Danks 1978

-1.7 Danks 1978

-23.9 Danks 1978

-23.5 Danks 1978

$0.6 \quad$ Danks 1978

1.1 Danks 1978

1.7 Danks 1978

2.8 Danks 1978

a Thermometer failed at this temperature in January.

review by Cannon \& Block [1988]). Lee et al. (1991) recently identified ice-nucleating bacteria within the gut of insects that are able to elevate the supercooling point of an insect model by $14^{\circ} \mathrm{C}$. Thus, in general, feeding insects are less cold-hardy than nonfeeding insects (Somme 1982).

Freeze-Tolerant Insects. Some overwintering insects tolerate extensive ice formation within their bodies. Freeze-tolerant insects occur among the Diptera, Hymenoptera, Coleoptera, Neuroptera, and Lepidoptera. A number of these insects produce ice-nucleating proteins in the hemolymph that elevate whole-body supercooling points to $\approx-8$ to $-10^{\circ} \mathrm{C}$ (Zachariassen \& Hammel 1976, Duman et al. 1991). Inoculative nucleation, caused by contact with external ice, is another mechanism that functions to limit supercooling and ensure freezing at temperatures only slightly below the freezing point of body fluids (Lee 1991). The induction of extracellular freezing at relatively high subzero temperatures (e.g., supercooling points in the range of $-8^{\circ} \mathrm{C}$ or warmer) is believed to decrease the chance of lethal intracellular freezing and allow time for cells to adjust to the osmotic changes caused by ice formation. Freeze-tolerant insects also accumulate low-molecular-weight cryoprotectants, as described for freezesusceptible species.

Phenological Synchronization of Cold-Hardening. In nature, the cold-hardening process begins before insects are exposed to subzero temperatures. Numerous studies demonstrate that two environmental cues, low temperatures and short photoperiods, trigger coldhardening (Lee 1989). Exposure to low temperatures $\left(0-5^{\circ} \mathrm{C}\right) \mathrm{stim}-$ ulates the accumulation of low-molecular-weight cryoprotectants (Storey \& Storey 1991). Low temperatures directly activate or inhibit specific enzymes that shunt carbon into biosynthetic pathways that result in sometimes multimolar concentrations of polyols. Likewise, short photoperiods can trigger the synthesis of antifreeze proteins called thermal hysteresis or antifreeze proteins (Duman et al. 1991). These proteins not only lower the supercooling and freezing points, but they also may protect freeze-tolerant insects from injury caused by ice crystals. Recent work (Knight $\&$ Duman 1986) demonstrates that these proteins inhibit recrystallization, a potentially lethal process in frozen insects. Almost all research concerning the environmental synchronization of the cold-hardening process in insects has focused on terrestrial insects.

Aquatic Insects. We began investigating the cold-hardiness of aquatic insects by surveying the supercooling points and the capacity for freeze tolerance of aquatic insects from a variety of major orders. We hypothesized that most species of aquatic insects-unlike terrestrial insects-would have limited abilities to supercool and would be freeze tolerant. Our hypothesis is consistent with that of Salt (1963), who suggested that freezing of external water causes inoculative freezing within insects. Some terrestrial insects experience inoculative freezing when they overwinter in moist habitats and come in contact with or are encased completely in ice (Somme 1982, Layne et al. 1990). Inoculative freezing presumably occurs when external crystals of ice grow and penetrate pores in the insect's cuticle or other orifices on the body, thereby inducing freezing of body fluids within the insect. Supercooling cannot prevent inoculative ice nucleation, thus only freeze-tolerant insects or those surrounded by an impermeable protective case are thought to survive this process. With the exception of some chironomids and caddisflies, aquatic insects lack protective cases, suggesting that those species that survive encasement in ice must tolerate inoculative freezing. Additionally, we hypothesized that aquatic insects of a given taxon would exhibit less variability in supercooling points than terrestrial insects, because aquatic insects are exposed to smaller fluctuations in temperature than terrestrial insects due to the thermal inertia of the aquatic environment.

Supercooling. We measured supercooling points for aquatic insects collected from shallow streams and ponds in southwestern Ohio during winter and summer in 1988. Measurements of supercooling points were made by placing individual insects that were not in contact with water next to a copper-constantan thermocouple. Insects were cooled at a rate of $1^{\circ} \mathrm{C}$ per minute, and the lowest temperature reached before the release of the latent heat of crystallization was recorded as the supercooling point. Our results supported both our hypotheses that aquatic insects have limited abilities to supercool and that supercooling points vary little within a given taxon. Mean supercooling points for seven different aquatic insect orders were elevated consistently relative to terrestrial insects and ranged from $-3.3^{\circ} \mathrm{C}$ for Ephemeroptera in winter to $-7.4^{\circ} \mathrm{C}$ for Coleoptera (Dytiscidae) in summer. The range of these values was low-only $3.1^{\circ} \mathrm{C}-$ and variability within taxa (orders and families) as measured by coefficients of variation ranged only from 0.06 to 0.37 . Supercooling points for freeze-tolerant larvae of the semiterrestrial; Antarctic chironomid, Belgica antarctica (Tacobs), range from $-10^{\circ} \mathrm{C}$ in summer to $\approx-5^{\circ} \mathrm{C}$ in winter (Lee \& Baust 1981). In contrast, mean super- 
cooling points for terrestrial insect taxa range from $\approx-5^{\circ} \mathrm{C}$ to as low as $-60^{\circ} \mathrm{C}$ (Somme 1982), and much variability exists within orders (Fig. 1).

Elevated supercooling points that closely correspond to our values also have been reported for larval or nymphal stages of Plecoptera, Trichoptera, and Ephemeroptera inhabiting subarctic streams in Alas$\mathrm{ka}$ (Oswood et al. 1991). Supercooling points ranged from -3 to $-7^{\circ} \mathrm{C}$ for winter-collected specimens. Interestingly, certain Diptera from Alaska exhibited much lower supercooling points than other taxa. Live dance flies (Diptera: Empididae) and Chironomidae thawed from frozen substrates exhibited mean supercooling points of -22.6 and $-11.0^{\circ} \mathrm{C}$, respectively. Possibly these flies possess an enhanced ability to supercool because they are less mobile than other aquatic taxa and consequently are more likely to become trapped in ice. Similarly, overwintering larvae of tree-hole mosquitoes have supercooling points as low as $-14.7^{\circ} \mathrm{C}$, which is probably advantageous to insects inhabiting microhabitats that freeze solid (Copeland \& Craig 1990). Among aquatic insects tested in Ohio, "water pennies" (Coleoptera: Psephenidae) exhibited the lowest mean supercooling point $\left(\bar{x}=-6.7^{\circ} \mathrm{C} ; \mathrm{SD}=2.46\right)$. This insect also may be insufficiently motile to relocate in deeper water where ice is unlikely to form, or the insect may be too large to enter the interstices between substrate particles-a habitat called the hyporheic zone- - where temperatures are moderated. It should be noted that supercooling points in the above studies and those reported by us probably overestimate aquatic insect supercooling points because they were determined using " $d r y$ " insects. These were insects that were lightly dried and therefore may have been less susceptible to inoculative freezing. Nevertheless, the values reported here demonstrate elevated supercooling points relative to terrestrial insects, and corrected values using "wet" insects would only magnify the elevation of supercooling-point temperatures.

An ecological explanation for consistently high supercooling points of aquatic stages of aquatic insects is that extensive supercooling capabilities are unnecessary because the frozen substrates of streams and ponds are often warmer and less variable than terrestrial habitats (Table 1). Also, the frequency of encountering subzero temperatures in aquatic habitats may not be great enough to select for enhanced supercooling capability in aquatic insects. Minimum daily field temperatures of the overwintering microhabitats of aquatic insects are needed over a latitudinal gradient and over a long period (decades) to assess the frequency of exposure to subzero temperatures. Alternatively, high supercooling-point values of aquatic insects may simply result from inoculative freezing that prevents aquatic insects from supercooling extensively. This explanation could be tested using cryomicroscopy to verify the occurrence of inoculative freezing.

Interestingly, our preliminary results suggest that terrestrial stages of aquatic insects have a greater capacity to supercool than aquatic stages of the same taxon. We determined mean supercooling points for adult terrestrial stoneflies (Plecoptera: Capniidae) collected in February in Ohio. Their mean supercooling point $\left(\bar{x}=-7.9^{\circ} \mathrm{C}\right.$; SD $= \pm 1.1)$ was significantly lower $(t$ test; $t=8.00, P<0.001)$ than the mean supercooling point of their nymphal stage $\left(\bar{x}=-4.1^{\circ} \mathrm{C}\right.$; $\mathrm{SD}= \pm 0.5)$. Likewise, adult caddisflies and mayfliés collected in summer also exhibited significantly lower supercooling points than their aquatic stages ( $t$ tests; $P<0.01$ ). It is likely that terrestrial life stages of aquatic insects, which either overwinter in terrestrial habitats or emerge during early spring, encounter subzero temperatures more frequently than aquatic stages. This would be particularly true in geographical regions experiencing low air temperatures but little or no snowfall.

Freeze Tolerance. Among terrestrial insects, those having elevated supercooling points often are freeze tolerant; this generality, however, may not apply to aquatic insects. Although aquatic stages of many aquatic insects possess relatively high supercooling points $(-3$

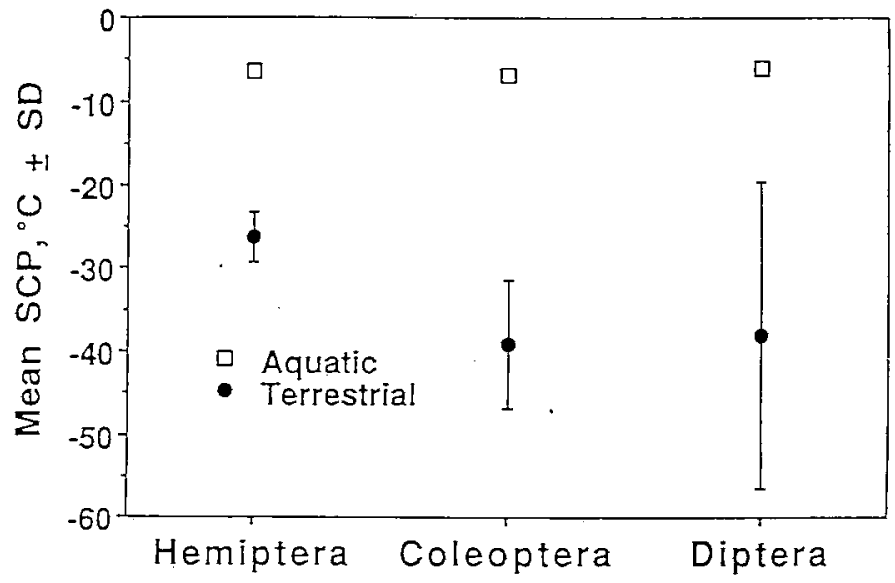

Fig. 1. Comparison of lowest mean supercooling points (SCP) for species of aquatic and terrestrial insects within the same order. Values for terrestrial species are from Somme (1982) and are for freeze-susceptible species. Values for aquatic species are from Moore \& Lee (unpublished data). Vertical bars represent one standard deviation. Standard deviations of means for aquatic orders range from 0.26 to 0.89 and are not visible on the graph.

to $-7^{\circ} \mathrm{C}$ ), it appears that few taxa are freeze tolerant. For example, only larvae of selected species from three dipteran families--Chironomidae, Empididae (dance fly larvae), and Culicidae (mosquito larvae)-exhibit high survival rates $(>40-50 \%)$ both in laboratory freezing experiments (Danks 1971, Copeland \& Craig 1990, Oswood et al. 1991) and thawing experiments using sediments and ice collected from aquatic habitats in late winter (Danell 1981, Olsson 1981, Andrews \& Rigler 1985, Copeland \& Craig 1990). Survival rates $>80 \%$ are not uncommon for chironomids thawed from frozen sediments in late winter (Lee \& Baust 1981, Oswood et al. 1991).

Insect orders that appear to be freeze susceptible (cannot survive temperatures lower than their supercooling point) include Ephemeroptera, probably Plecoptera, and many species of Trichoptera. In our studies, no individuals from these orders revived following supercooling-point determinations; however, we determined supercooling points using "dry" insects, so desiccation may have contributed to mortality. Other supportive evidence is that no live Ephemeroptera have been recovered from either laboratory freezing experiments (Olsson 1981) or from frozen sediments collected in the field (Oswood et al. 1991). In fact, very few Ephemeroptera or Plecoptera (and to a lesser extent, Trichoptera) are ever found in frozen substrates or ice. Researchers in Alaska suggest that the absence of these insects in frozen areas of ponds and streams indicate that they occupy microhabirats that never freeze, or they seasonally move into deep water that remains unfrozen (Oswood et al. 1991). Many members of Odonata also may be freeze susceptible. Although Corbet et al. (1960) report that two Odonata genera survive freezing, other laboratory and field experiments (Daborn 1971, Sawychn \& Gillott 1975, Duffy \& Liston 1985) demonstrate low survival rates (usually $\leq 20 \%$ ) for damselfly nymphs in ice at relatively warm subzero temperatures $\left(-4-\right.$ to $\left.8^{\circ} \mathrm{C}\right)$, which approximate their supercooling points (unpublished data).

The generalizations mentioned above concerning the lack of freeze tolerance among aquatic insects are preliminary, because the data is limited and the methods currently used to determine freeze tolerance suffer from several shortcomings. Laboratory freezing experiments usually do not simulate natural conditions because abnormal rates of cooling or thawing are used, and submerged sediments or vegetation comparable to natural conditions are lacking in freezing con-tainers. Experimental artifacts such as an increase in the mechanical pressure of ice as it expands against rigid walls of experimental containers also exist. Although these problems can be avoided, good 
tests of freeze tolerance are needed in the field to determine which taxa can survive encasement in ice and how the duration of freezing and different substrates and microhabitats influence survival. Such tests might include placing wire baskets containing rocks, sediments, or leaf packs flush with the substrate in frozen (shallow) and unfrozen (deep) regions of a pond or stream and retrieving them at regular time intervals throughout winter and the spring thaw period. Thermocouples appropriately placed in the field and attached to automatic recorders could provide daily or more frequent records of temperatures experienced by the insects. When thawing the retrieved samples in the laboratory, a temperature regime and time duration that mimics natural conditions should be used. Past studies have not done this because little is known about the temperature of ice during the spring as it warms and thaws. For example, we need to know if refreezing is likely to occur during a late winter night and, if so, how often an insect is frozen and refrozen during a given season.

Mechanisms of freeze injury are unknown among aquatic insects. Proposed mechanisms include oxygen stress, desiccation, and mechanical stress from external ice crystals. Resistance to anoxia is probably an important adaptation for aquatic insects that are freeze tolerant or encased in ice, because insignificant amounts of oxygen diffuse through solid ice. Tolerance of winter anoxia has been reported for the mayfly Cloeon dipterum L. (Ephemeroptera: Baetidae), which occurs in shallow Swedish ponds where it occupies anoxic waters below the ice surface for 3-4 mo (Nagell 1980). C. dipterum and other aquatic insects that survive encasement in ice may have the ability to switch to anaerobic metabolism (Tauber et al. 1986).

Aquatic insects that are freeze tolerant also must be able to tolerate desiccation, because extracellular freezing causes considerable cellular dehydration. Interestingly, aquatic insects that remain viable upon dehydration are likely to be freeze tolerant. A remarkable example of this is the chironomid Polypedilum vanderplanki Hinton, which occurs in temperate rock pools in Africa where it experiences repeated dehydration. In the desiccated state, this insect can tolerate temperatures as low as $-270^{\circ} \mathrm{C}$, but in the fully hydrated state it does not survive such treatment (Hinton 1960).

Mechanical pressure of impinging ice crystals and inoculative freezing may cause structural injury to the insect. Such injury might be lessened or prevented by protective morphological structures such as cocoons or rigid cuticles (Somme 1982, Tauber et al. 1986). Interestingly, one study demonstrated higher rates of freezing survival among chironomids with winter cocoons than those without (Danks 1971). But overwintering populations of chironomids.sometimes contain a low proportion of cocooned individuals, which suggests that the selective adyantage of cocoons may be low (Oswood et al. 1991). Future observations with cryomicroscopy will help evaluate the effectiveness of cocoons and cases in protecting aquatic insects from the pressure of external ice crystals and inoculative freezing.

Some types of ice appear to be less injurious to aquatic insects than others. For example, several studies have reported $100 \%$ survival of insects (Plecoptera, Ephemeroptera, Trichoptera, Diptera, and Coleoptera) frozen in anchot ice (Benson 1955, Brown et al. 1953). One comparative study in a Montana river reported that all mayfly and stonefly nymphs survived and caddisfly and chironomid larvae recovered from anchor ice, whereas no organisms survived thawing from pieces of sheet (surface) ice. It is likely that slushy anchor ice, composed of loosely arranged crystals, contains air spaces that mitigate injury from mechanical stress and anoxia. When loosened from the streambed, however, anchor ice may indirectly cause insect mortality by scouring the substrate and dislodging insects that subsequently are consumed by fish such as trout (Maciolek \& Needham 1951).

Bebavioral Avoidance of Freezing by Aquatic Insects. If inoculative freezing occurs when an insect is encased in ice, then avoidance of areas of ice formation may be essential for most aquatic insects because many appear to be freeze susceptible and have relatively poor supercooling abilities. Assuming that at least parts of the aquatic habitat freeze during winter, then aquatic insects may respond behaviorally in one of two ways: (1) by choosing an initial overwintering site that has a low probability of freezing and remaining there, or (2) by moving to a new overwintering site when ice begins to form near the insect. Certain species of waterstriders (Hemiptera: Gerridae) exhibit the first behavioral response; they overwinter in bankside vegetation or litter above shoreline (Nummelin \& Vepsalainen 1982 , Kaufmann 1971) where the probability of becoming trapped in ice is reduced greatly. Of course, insects in pupal stages or within sealed cases (certain Trichoptera) and cocoons (Diptera) will be incapable of movement. If the selection pressure to avoid encasement in ice is strong, these insects may be more likely than mobile insects to overwinter in deep water.

The second behavioral response is probably most common among winter-active insects. For example, monthly sampling across a northern Swedish river revealed that mayflies in the littoral zone moved laterally into deeper, ice-free water when the littoral substrate began freezing in early winter (Olsson 1983). Similar seasonal changes in the depth distribution of plecopterans and trichopterans have been reported in rivers (summarized by Olsson [1983]) and in ponds for trichopterans (Tozer et al. 1981) and chironomids (Andrews \& Rigler 1985). Moving from shore water into deeper water is not always adaptive, however, particularly for insects dwelling in anoxic ponds. In Great Britain, a mayfly that is intolerant of anoxia inhabits anoxic frozen ponds by moving to oxygen-rich waters near shore (Brittain \& Nagell 1981). As oxygen concentrations diminish in the pond, mayfly nymphs become positively phototactic and negatively thermotactic and move near the surface along the shoreline where cooler oxygenated meltwater accumulates.

In streams, small aquatic insects may avoid ice or superficial frozen substrates by migrating vertically into the unfrozen hyporheic.zone. This habitat of interstices between substrate particles sometimes extends laterally several meters or kilometers from the stream channel. Within the hyporheic zone, water temperatures can be considerably warmer than in the main stream channel. For example, in northwestern Montana, capniid stoneflies are common in $10-\mathrm{m}$ wells on the floodplain of the Flathead River, where temperatures of well water range from 5 to $7^{\circ} \mathrm{C}$ year-round (Stanford \& Ward 1988). Recent laboratory experiments also verify that aquatic insects (Ephemeroptera, Plecoptera, Trichoptera, and Diptera) move into warmer, deeper substrates when the surface substrate is frozen (Oswood et al. 1991). Migrating into the hyporheic zone is a behavioral strategy that probably is limited to small insects (e.g., capniid stoneflies), which can move easily in the interstices of the substrate (Pugsley \& Hynes 1986). Larger stream animals may escape freezing by using another behavioral strategy-entering stream drift when ice begins to form. This strategy, however, may be risky because insects may be swept toward and lodged in ice further downstream.

\section{Ecological Consequences and Management Applications}

Consequences for Individual Insects. The ecological consequences of insect overwintering are numerous and largely unexplored. At the level of the individual, metabolic costs and benefits of cold-hardiness need to be identified. Manufacturing cryoprotectants requires energy, particularly for insects that accumulate significant amounts: up to $25 \%$ of the wet mass of overwintering Bracon cephi (Gahan) ( $\mathrm{Hy}$ menoptera: Braconidae) is glycerol (Salt 1961). Thus, the amount of cryoprotectants that are synthesized, and hence the capacity to coldharden, may be influenced by food abundance during summer or early fall. If food shortages reduce the concentration of synthesized cryoprotectants and the capacity for cold-hardening, perhaps limiting 
the quantity or quality of food available to pest insects at a critical point in their life cycles-and thus increasing overwintering mortality-may constitute an effective pest management strategy. For example, soybean strains differ in their extent and type of secondary chemical defenses (Chiang et al. 1986, Kogan 1986). High concentrations of such plant defenses may limit production of cryoprotectants in herbivorous pests such as the Mexican bean beetle, Epilachna varivestis Mulsant, and enhance overwintering mortality. However, no tests of this hypothesis have been conducted.

Another intriguing idea is that mild winters, with extended periods of warm temperatures punctuated by occasional cold snaps, may decrease overwintering survival. Exposure to warm temperatures causes the rapid loss of cryoprotectants and cold-hardiness (Lee 1989) and may make insects vulnerable to brief periods of low temperature. Mild winters also may increase metabolic rates to the point that energy reserves are excessively depleted and thus unavailable in the spring for growth, development, and other activities. Laboratory experiments quantifying mortality rates after exposure to such thermal regimes could test this idea.

Population. Mortality rates inflicted by subzero temperatures may influence the age structure and subsequent reproductive rates of populations. Laboratory research with tree-hole mosquito larvae collected from northern Indiana indicates that the-magnitude, duration, and repeated exposure to subzero temperatures may influence the age structure of overwintering cohorts (Copeland \& Craig 1989, 1990). For example, second-instar Anopheles barberi Coquillett (Diptera: Culicidae) exhibit higher survival than third instars following a 24-h exposure to $-15^{\circ} \mathrm{C}$, the lowest recorded temperature in a frozen tree hole. Thus, severe winters may favor second instars, which reproduce later and probably have lower fitness than third instars (Copeland \& Craig 1989). Assessments of the effects of overwintering mortality relative to other sources of mortality are needed and could be determined using K-factor analysis (Varley et al. 1973, Price 1984). This method, however, is more tractable for small pond habitats than for running waters, because insects in streams and rivers leave the study area when they enter stream drift. In running waters, comparative studies of mortality and reproduction among individuals frozen in shallow waters or inhabiting deeper, open water should prove fruitful. This approach was used successfully to study a snail population in a northern Swedish river (Olsson 1988). Surprisingly, this study revealed that snails frozen in ice for $4 \mathrm{mo}$ had significantly higher rates of survival and subsequent reproduction than those in the deeper, unfrozen region of the river. The author suggests that fish predation on unfrozen snails was responsible for the differential survival of the two groups. The increased reproduction of frozen snails may have resulted from an energetic advantage: frozen insects are known to have lower metabolic rates than unfrozen insects. If unfrozen, active snails cease feeding at winter temperatures or cannor consume sufficient resources to meet their energetic demands then energy reserves will become depleted, possibly causing reduced reproduction. Studies similar to the Swedish snail study need to be conducted with aquatic insects to evaluate the effect of encasement in ice on the mortality and reproductive rates of populations.

Surprisingly little is known about the role that overwintering mortality plays in defining the geographical limits of many insect species. Both latitudinal and altitudinal limits of species may be determined by overwintering capability, or duration of growing season, or both. Studies of insect biogeography at high latitudes show that among terrestrial insects, Diptera and Hymenoptera become proportionally more abundant from south to notth up to the low arctic (Danks 1978). Likewise, a study of insect fauna in Alaskan streams and rivers showed that Diptera (especially Chironomidae), as well as Plecoptera (especially Nemouridae), increased their proportional representation in the aquatic insect fauna at higher latitudes (Oswood 1989). These distributional patterns may be controlled by historical events (e.g., glaciation and invasions of river systems), by quality and quantity of food resources, or by physiological capabilities (cold-hardiness) of the insects. Further studies of insect cold-hardiness are needed to elucidate the influence that overwintering plays in defining limits of geographical range.

Warmer winter temperatures resulting from global climate warming could have a profound effect on the survival rates of overwintering populations. In geographical regions where overwintering mortality currently limits population density, warmer winters could result in increased survival in winter and longer growing seasons. These conditions could allow invasion of new species, as well as population outbreaks of resident pest species. Such a scenario is suggested in a recent review of the potential effects of global climate change on agricultural insect pests (Stinner et al. 1989). By determining the overwintering mortality of pest species in the field and in the laboratory at warmer projected temperatures, we may be able to predict the population response of pest species to warmer winters and use this information to develop strategies for integrated pest management.

Knowledge of insect cold-hardiness also can be useful in understanding and predicting potential range expanisions of introduced species. An outstanding example is a recent study of the mosquito Aedes albopictus (Skuse), a new invader in the southern United States (Hawley et al. 1987). Cold-hardiness characteristics and photoperiodic sensitivity of the overwintering egg stage were used to establish that the invading Ae. albopictus strain most likely originated from temperate rather than tropical Asia. Climatic records for northern Asia and the United States then were compared to predict that this aggressive mosquito, a vector of dengue fever, has the potential to colonize the northern and eastern United States.

Species Interactions. In winter, species interactions, such as competition and predation, occur in both terrestrial and aquatic habitats, but they are studied little. Anecdotal information suggests that interand intraspecific competition for overwintering sites may be intense for terrestrial insects (Danks 1978), particularly those that aggregate in specific overwintering sites (e.g., carabid beetles in tree stumps). These insects may exhibit interference competition when appropriate overwintering sites are in short supply. Interference competition is a direct behavioral action (aggression, release of allelochemicals, or usurping of space) that harms or kills the competitor (Begon et al. 1990). This type of competition may result in dominant insects securing prime overwintering sites while excluding subdominants. To our knowledge, no experimental study has evaluated the occurrence of intra- or interspecific competition for overwintering sites among insects. Such studies could be done by performing a field experiment using an insect species that does not feed during winter, thus eliminating competition for food. Either insect density or abundance of overwintering sites (fallen logs, leaf packs in streams, etc.) could be enhanced or reduced on experimental plots. Subsequent reproduction and winter survival would be compared among control treatment plots.

Predation may have a much greater effect on terrestrial overwintering populations than on populations in frozen aquatic habitats. Terrestrial insects are more vulnerable to predators because of their exposure to endothermic predators that are more efficient than ectothermic fish predators in streams and lakes. Also, terrestrial insects lack an ice refuge from predators, and they may be more locally abundant if aggregated in overwintering sites. The vulnerability of overwintering terrestrial insects is demonstrated well by predation rates of small mammals and other insect predators on sawfly cocoons; $66-70 \%$ of the overwintering cocoons are typically consumed (Danks 1978). Furthermore, most overwintering insects in terrestrial environments are in a state of dormancy and consequently are nearly immobile. They avoid predation by cryptic coloration or well-hidden refuges (Tauber et al. 1986). In aquatic systems, the idea that en- 
trapment in ice may be an effective defense against predation needs to be evaluated. Although ice encasement increases survival of Swedish snails, this may not occur for other aquatic species, many of which lack a durable case for resisting mechanical stress from ice.

\section{Interdisciplinary Research Opportunities}

In conclusion, insect cold-hardiness, a relatively young field of research, is a fascinating blend of entomology, physiology, and ecology. Although this area of research has largely focused on insect physiology, there are many interesting opportunities for ecologists who are interested in probing the role that insect cold-hardiness plays in influencing the distribution and abundance of species. The effects of low winter temperatures and ice on the structure of aquatic communities are particularly intriguing for study. This interdisciplinary research area has and will continue to bring advancements in the areas of pest management, species invasions, and general insect biology.

\section{Acknowledgment}

Our research described in this report was supported in part by a grant from the National Science Foundation, DCB-8811317. We also thank Mark Oswood, Keith Miller, and John Irons for sharing their results concerning the cold-hardiness of Alaskan stream insects.

\section{References Cited}

Andrews, D. \& F. Rigler. 1985. The effects of an Arctic winter on benthic invertebrates in the littoral zone of Char Lake, Northwest Territories. Can. J. Zool. 63: 2825-2834.

Baust, J. G. 1976. Temperature buffering in an arctic microhabitat. Ann. Entomol. Soc. Am. 69: 117-119.

Begon, M., J. L. Harper \& C. R. Townsend. 1990. Ecology: individuals, populations, and communities, 2nd ed. Blackwell Scientific, Boston.

Bengtsson, B. E. 1981. The growth of some ephemeropteran nymphs during winter in a north Swedish river. Aquat. Insects 3: 199-208.

Benson, N. G. 1955. Observations on anchor ice in a Michigan trout stream. Ecology 36: 529-530.

Berte, S. B. \& G. Pritchard. 1983. The life history of Glyphopsyche irrorata (Trichoptera, Limnephilidae): a caddisfly that overwinters as an adult. Holarct. Ecol. 6: 69-73.

1986. The life histories of Limnepbilus externus Hagen, Anabolia bimaculata (Walker), and Nemotaulius hostilis (Hagen) (Trichoptera, Limnephilidae) in a pond in southern Alberta, Canada. Can. J. Zool. 64: 23482356.

Brittain, J. E. \& B. Nagell. 1981. Overwintering at low oxygen concentrations in the mayfly Leptopblebia vespertina. Oikos 36: 45-50.

Brown, C.J.D., W. D. Clothier \& W. Alvord. 1953. Observations on ice conditions and bottom organisms in the West Gallatin River, Montana. Proc. Mont. Acad. Sci. 13: 21-27.

Cannon, R.J.C. \& W. Block. 1988. Cold tolerance of microarthropods. Biol. Rev. Camb. Philos. Soc. 63: 23-77.

Chiang, H.-S., D. M. Norris, A. Ciepicla, A. Oosterwyk, P. Shapiro \& M. Jackson. 1986. Comparative constitutive resistance in soybean lines to Mexican bean beetle. Entomol. Exp. Appl. 42: 19-26.

Copeland, R. S. \& G. B. Craig, Jr. 1989. Winter cold influences the spatial and age distributions of the North American treehole mosquito Anopheles barberi. Oecologia (Berl.) 79: 287-292.

1990. Cold hardiness of tree-hole mosquitoes in the Grear Lakes region of the United States. Can. J. Zool. 68: 1307-1314.

Corbet, P. S., C. Longfield \& N. W. Moore. 1960. Dragonflies. Collins, London.

Daborn, G. R. 1971. Survival and mortality of coenagrionid nymphs (Odonata: Zygoptera) from the ice of an aestival pond. Can. J. Zool. 49: 569571.

1974. Biological features of an aestival pond in western Canada. Hydrobiologia 44: 287-299.
Danell, K. 1981. Overwintering of invertebrates in a shallow northern Swedish lake. Int. Rev. Gesamten Hydrobiol. 66: 837-845.

Danks, H. V. 1971. Overwintering of some north temperate and arctic Chironomidae. II. Chironomid biology. Can. Entomol. 103: 1875-1910.

1978. Modes of seasonal adaptation in the insects. I. Winter survival. Can. Entomol. 110: 1167-1205.

Duffy, W. G. \& C. R. Liston. 1985. Survival following exposure to subzero temperatures and respiration in cold acclimatized larvae of Enallagma boreale (Odonata: Zygoptera). Freshwater Invertebr. Biol. 4: 1-7.

Duman, J. D., L. Xu, L. G. Neven, D. Tursman \& D. W. Wu. 1991. Hemolymph proteins involved in insect subzero temperature tolerance: ice nucleators and antifreeze proteins, pp. 94-127. In R. E. Lee \& D. L. Denlinger [eds.], Insects at low temperature. Chapman \& Hall, New York.

Ellis, R. J. 1978. Over-winter occurrence and maturation of gonads in adult Psychoglypha subborealis (Banks) and Glyphopsyche irrorata (Fabricius). Pan-Pac. Entomol. 54: 178-180.

Harper, P. P. \& H.B.N. Hynes. 1972. Life-histories of Capniidae and Taeniopterygidae (Plecoptera) in southern Ontario. Arch. Hydrobiol. 40: 274314 (Suppl.).

Hawley, W. A., P. Reiter, R. S. Copeland, C. B. Pumpuni \& G. B. Craig, Jx. 1987. Aedes albopictus in North America: probable introduction in used tires from northern Asia. Science 236: 1114-1116.

Hinton, H. E. 1960. A fly larva that tolerates dehydration and temperatures of $-270^{\circ}$ to $102^{\circ} \mathrm{C}$. Nature (Lond.) 188: 336-337.

Kaufmann, T. 1971. Ecology, biology and gonad morphology of Gerris rufoscutellatus (Hemiptera: Gerridae) in Fairbanks, Alaska. Am. Midl. Nat. 86: 407-416.

Knight, C. A. \& J. G. Duman. 1986. Inhibition of recrystallization of ice by insect thermal hysteresis proteins: a possible cryoprotective role. Cryobiology 23: 256-262.

Kogan, M. 1986. Natural chemicals in plant resistance to insects. Iowa State J. Res. 60: 501-527.

Layne, J. R., R. E. Lee \& J. L. Huang. 1990. Inoculation triggers freezing at high subzero temperatures in a freeze-tolerant frog (Rana sylvatica) and insect (Eurosta solidaginis). Can. J. Zool. 68: 506-510.

Lee, R. E. 1989. Insect cold-hardiness: to freeze or not to freeze. BioScience 39: 308-313.

1991. Principles of insect low temperature tolerance, pp. 17-46. In R. E. Lee \& D. L. Denlinger [eds.], Insects at low temperature. Chapman \& Hall, New York.

Lee, R. E. \& J. G. Baust. 1981. Seasonal patterns of cold-hardiness in Antarctic terrestrial arthropods. Comp. Biochem. Physiol. 70A: 579-582.

Lee, R. E., J. M. Strong-Gunderson, M. R. Lee, K. S. Grove \& T. J. Riga. 1991. Isolation of ice nucleating active bacteria from insects. J. Exp. Zool. (in press).

Maciolek, J. A. \& P. R. Needham. 1951. Ecological effects of winter conditions on trout and trout foods in Convict Creek, CA. Trans. Am. Fish. Soc. 81: 202-217.

Marchand, P. J. 1982. An index for evaluating the temperature stability of a subnivean environment. J. Wildl. Manage. 46: 518-520.

Merritt, R. W., D. H. Ross \& G. J. Larson. 1982. Influence of stream temperature and seston on the growth and production of overwintering larval black flies (Diptera: Simuliidae). Ecology 63: 1322-1331.

Nagell, B. 1980. Overwintering strategy of Cloeon diptertum (L.) larvae, pp. 259-264. In J. F. Flannagan \& K. E. Marshall [eds.], Advances in Ephemeroptera biology. Plenum, New York.

Neldner, K. H. \& R. W. Pennak. 1955. Seasonal faunal variations in a Colorado alpine pond. Am. Midl. Nat. 53: 419-430.

Nummelin, M. \& K. Vepsalainen. 1982. Densities of wintering waterstriders Gerris odontogaster (Heteroptera) around a breeding pond. Ann. Entomol. Fenn. 48: 60-62.

Olsson, T. I. 1981. Overwintering of benthic macroinvertebrates in ice and frozen sediment in a north Swedish river. Holarct. Ecol. 4: 161-166.

1983. Seasonal variation in the lateral distribution of mayfly nymphs in a boreal river. Holarct. Ecol. 6: 333-339.

1984. Winter sites and cold-hardiness of two gastropod species in a boreal river. Polar Biol. 3: 227-230.

1988. The effect of wintering sites on the survival and reproduction of Gyraulus acronicus (Gastropoda) in a partly frozen river. Oecologia (Berl.) 74: $492-495$.

Oswood, M. W. 1989. Community structure of benthic invertebrates in 
interior Alaskan (USA) streams and rivers. Hydrobiologia 172: 97-110.

Oswood, M. W., L. K. Miller \& J. G. Irons. 1991. Overwintering of freshwater benthic macroinvertebrates, pp. 360-375. In R. E. Lee \& D. L. Denlinger [eds.], Insects at low temperature. Chapman \& Hall, New York.

Price, P. W. 1984. Insect ecology, 2nd ed. Wiley, New York.

Pugsley, C. W. \& H.B.N. Hynes. 1986. Three-dimensional distribution of winter stonefly nymphs, Allocapnia pygmaea, within the substrate of a southern Ontario river. Can. J. Fish. Aquat. Sci. 43: 1812-1817.

Ring, R. A. \& D. Tesar. 1981. Adaptations to cold in Canadian Arctic insects. Cryobiology 18: 199-211.

Salt, R. W. 1961. Principles of insect cold-hardiness. Annu. Rev. Entomol. 6: $55-74$.

1963. Delayed inoculative freezing of insects. Can. Entomol. 95: 11901202.

Sawchyn, W. W. \& C. Gillott. 1975. The biology of two related species of coenagrionid dragonflies (Odonata: Zygoptera) in western Canada. Can. Entomol. 1.07: 119-128.

Somme, L. 1982. Supercooling and winter survival in terrestrial arthropods. Comp. Biochem. Physiol. 73A: 519-543.

Stanford, J. A. \& J. V. Ward. 1988. The hyporheic habitat of river ecosystems. Nature (Lond.) 335: 64-66.

Stinner, B. R., R.A.J. Taylor, R. B. Hammond, F. F. Purrington, D. A. McCartney, N. Rodenhouse \& G. W. Barrett. 1989. Potential effects of climate change on plant-pest interactions, pp. 8/1-8/35. In J. B. Smith $\&$ D. A. Tirpak [eds.], The potential effects of global climate change on the United States. U.S. Environmental Protection Agency, Washington, D.C.

Storey, K. B. \& J. M. Storey. 1991. Biochemistry of cryoprotectants, pp. 64-93. In R. E. Lee \& D. L. Denlinger [eds.], Insects at low temperature. Chapman \& Hall, New York.

Tauber, M. J., C. A. Tauber \& S. Masaki. 1986. Seasonal adaptations of insects. Oxford Univ., New York.

Tozer, W. 1979. Underwater behavioural thermoregulation in the adult stonefly, Zapada cinctipes. Nature (Lond.) 281: 566-567.

Tozer, W., V. H. Resh \& J. O. Solem. 1981. Bionomics and adult behavior of a lentic caddisfly, Nectopsyche albida (Walker). Am. Midl. Nat. 106: $133-144$.

Varley, G. C., G. R. Gradwell \& M. P. Hassell. 1973. Insect population ecology: an analytical approach. Univ. of California, Berkeley.

Zachariassen, K. E. \& H. T. Hammel. 1976. Nucleating agents in the haemolymph of insects tolerant to freezing. Nature (Lond.) 262: 285-287.

Received for publication 31 October 1990; accepted 12 February 1991.

Marianne V. Moore is an assistant professor of aquatic ecology in the Department of Biological Sciences at Wellesley College, Wellesley, Mass. 02181. Richard E. Lee, Jr., is an associate professor in the Department of Zoology at Miami University, Hamilton, Obio 45056. 